\title{
Contribution to the world: a lesson from Dr. Lee Jong-Wook
}

\author{
Kyu-Chang Wang
}

Received: 2 May 2014 / Accepted: 19 May 2014

(C) Springer-Verlag Berlin Heidelberg 2014

Thank you, Dachling, for the introduction. It is my great honor to be introduced by Dr. Pang.

\section{Prologue: Do you know this man?}

Do you know the man in Fig. 1?

Yes, he is Mr. Ki-Moon Ban who was born in 1944 in Korea before its liberation from Japan. At the age of 17, he had an opportunity to visit San Francisco as a winner of an English essay contest sponsored by the Red Cross. There, he met President John F. Kennedy and dreamed of being a diplomat. He, then, entered Seoul National University, majoring in international relations, and earned a master's degree from the John F. Kennedy School of Government at Harvard University. In 2007, he became the secretary general of the United Nations (UN). He is now in his second term [1].

Do you know the man in Fig. 2?

He is Dr. Jong-Wook Lee, a former director general of the World Health Organization (WHO). He is of similar age as Mr. Ban. He is the first Korean leader of such a large international organization.

This article was presented at the 41st International Society for Pediatric Neurosurgery (ISPN) annual meeting in Mainz on October 2, 2013 as the Presidential Address.

K.-C. Wang $(\triangle)$

Division of Pediatric Neurosurgery, Seoul National University

Children's Hospital, 101 Daehak-ro, Jongno-gu, Seoul 110-769,

South Korea

e-mail: kcwang@snu.ac.kr

\section{Challenges for Korea from the late sixteenth century: from one of the leading countries in East Asia to one of the poorest countries in the world}

During the period of the Koryo Dynasty (tenth-fourteenth centuries), Korea was one of the most active countries of the world. It traded with many foreign powers, including Arab countries. The name "Korea" comes from this Koryo Dynasty. Metal type-printing was invented in 1377. The book "Jikjisimche-yojeol (直指心體要節), ” which preceded Gutenberg by 78 years, was printed by metal type and designated a UNESCO (United Nations Educational, Scientific, and Cultural Organization) World Record Heritage in 2001. Another metal type-print from the Koryo Dynasty, "Jeungdo-gaja (證道 歌字),” from 1239, has been found but is not yet widely accepted in academic circles. Another treasure of the Koryo Dynasty is blue porcelain, which is famous for its subdued beauty and delicacy.

During the Chosun Dynasty, which was established in the late fourteenth century, Korea remained one of the leading countries in social and natural sciences and culture in East Asia until the sixteenth century. However, after the invasions by Japan at the end of the sixteenth century and the Chinese Ching Dynasty in the seventeenth century, Korea began a slow decline.

The period of occupation by Japan (1910-1945) was the most difficult in the history of Korea. Most of Korea's resources were taken to Japan, and many Korean people had to die for the Japanese Empire.

Korea was liberated from Japan in 1945. Liberation was a great joy and blessing, but although Japan had caused the war, Korea was divided at the 38 th parallel north. There were serious resource shortages and keen social conflicts between capitalism and socialism, with the USA on one side, the Soviet Union on the other, and nationalism in the middle. Society was plagued by poverty, instability, and insecurity. Two 


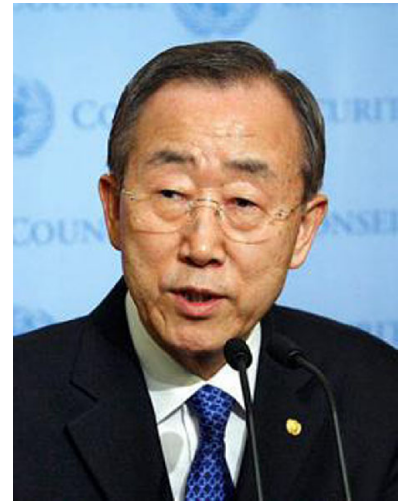

Fig. 1 Mr. Ki-Moon Ban, the current secretary general of the United Nations (from the webpage of the United Nations, http://www.un.org/)

governments were established in the Korean Peninsula. In 1950, Soviet Union-supported North Korea initiated the Korean War, which lasted for 3 years. Soon, the South was supported by the UN. Later, China invaded. In 1953, both sides agreed to an armistice with a de-militarized zone that has continued to exist for over 60 years.

The cost of the Korean War was enormous. A huge number of people were killed or wounded, with a confirmed death toll of $1,750,000$. Korea experienced extensive devastation in all aspects. In this time of extreme difficulty, other countries lent support, led primarily by the UN and USA, including food, clothing, houses, fuel, medicine, education, and construction materials. Many organizations participated in the aid to Korea, including the UN Korean Reconstruction Agency (UNKRA), US Operations Mission (USOM), US International Cooperation Administration (US ICA), US Agency for International Development (USAID), US Peace Corps, US Fulbright Education and Cultural Exchange Program, and US China Medical Board. When I was an elementary school student, the USAID $\log$ o (Fig. 3) was ubiquitous, appearing on food, clothing, boxes, and cement blocks. At that time, each elementary school student received a handful of dried sweet milk powder every day. I still remember how delicious that powdered milk was.

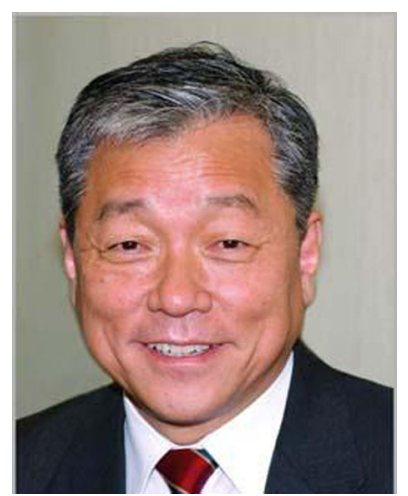

Fig. 2 Dr. Jong-Wook Lee, a former director general of the World Health Organization (courtesy of Jun-Wook Kwon, M.D., DrPH)

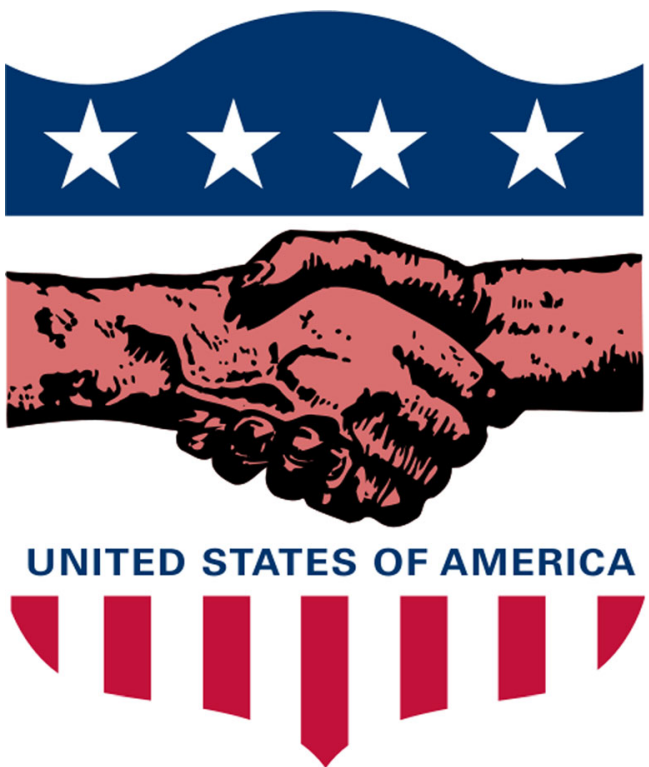

Fig. 3 An old logo of the United States Agency for International Development (USAID) (from Wikipedia, http://en.wikipedia.org/)

Korea was one of the poorest countries in the world. The gross domestic product (GDP) per capita in 1962 was only US\$87. In 1961, General Chung-hee Park staged a coup d'etat beginning a dictatorship that lasted over 18 years. In addition, there were endless local military conflicts and terrorist activities initiated by the North.

\section{Dr. Jong-Wook Lee: dreamed of "contribution to the world" during the "period of difficulty"}

Dr. Jong-Wook Lee was born in 1945 just before Korea's liberation from Japan. He initially entered Seoul National University College of Engineering. However, at the age of 24, he re-entered Seoul National University College of Medicine. At this time, Korea was still plagued by widespread poverty. As a medical student, Dr. Lee volunteered to care for leprosy patients in a suburb of Seoul. There, he met and married a fellow volunteer Miss Reiko Kaburaki from Japan. Dr. Lee was a man of dream (Fig. 4a). After graduating from school, he practiced at a small hospital in a small Korean town. There, he spent happy days with his wife Reiko and son Choong-Ho (Fig. 4b) [2].

In 1979, Dr. Lee earned a master's degree in Public Health at the University of Hawaii. Then, he went to the Lyndon B. Johnson Tropical Medical Center in American Samoa, where he was called the "Schweitzer of Asia." In 1983, he joined WHO as a leprosy consultant in Fiji. In 1986, he moved to the Western Pacific Regional Office in Manila to serve as the Regional Adviser on Chronic Diseases and the Regional Leprosy Control Program. He subsequently became the head of Polio Eradication Initiatives, with the yearly number of 
Fig. 4 Early days of Dr. JongWook Lee: a man of dream. a When he was a student of Seoul National University College of Medicine. (b) His wife Reiko and son Choong-Ho (courtesy of JunWook Kwon, M.D., DrPH)
A

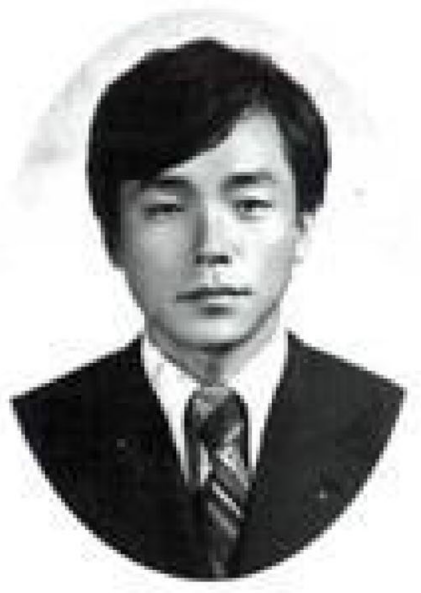

B

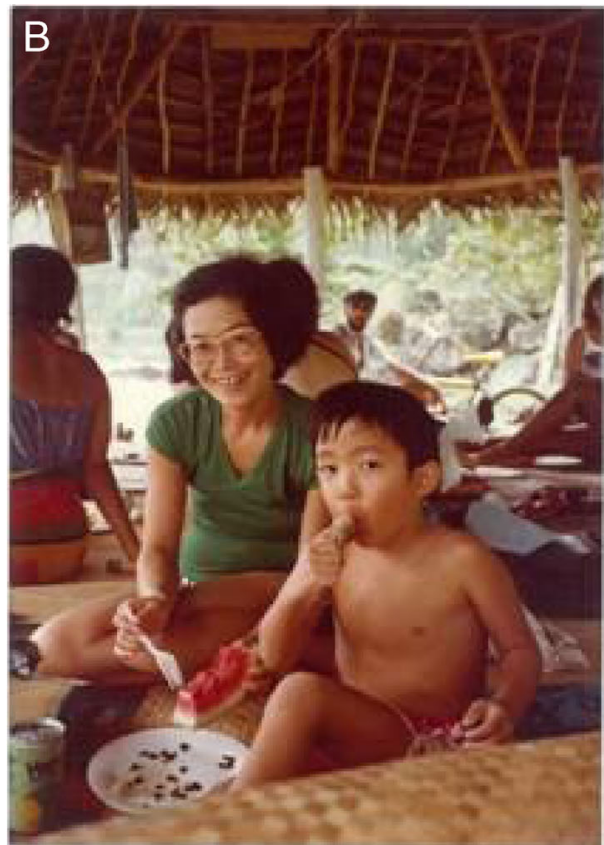

poliomyelitis patients dropping from 6,000 to 700 during his term. In 1994, Dr. Lee relocated to the WHO headquarters in Geneva, first serving as the director of the Global Program on Vaccines and Immunization and later as the executive secretary of the Children's Vaccine Initiative. During this time, he was dubbed the "Vaccine Czar" by the magazine, Scientific American. The fund grew from US\$15 million to US\$70 million. Dr. Lee's achievements in polio eradication were outstanding. During a visit in Africa in the midst of a battle, Dr. Lee stopped the combat for a few days to administer polio vaccinations to the soldiers, who then resumed combat. His enthusiasm was astounding. In 2000, he became the director of the Stop Tuberculosis (TB) Department at the WHO, where he proceeded to gather over 250 international partners. The Boston Globe wrote that Dr. Lee induced former antagonists to work together. In 2003, he became the director general of the WHO. During his term, he sought to address numerous issues, including tobacco control, international health regulation, avian influenza, tsunamis, and earthquakes. Providing advance warnings of and leading strong responses to avian influenza and severe acute respiratory syndrome (SARS) epidemic and working to eradicate polio are examples of his great achievements. He was a man of action, a man of response, and a man of compassion (Fig. 5) [2].

In 2005, Dr. Lee spoke to the medical students at Seoul National University and Yonsei University. There, he said, "Do not chase 'money'. You must have a dream. I really hate young medical doctors who do not have their own dreams." Yes, a dream requires more than just imagination. It requires a deep passion for a true value.

\section{Pediatric neurosurgery in Korea: sprouted from seeding} and nourishing by the world

Craniotomies began in the 1940s in Korea but were not initially common. "Western neurosurgery" was introduced during the Korean War, and several Korean military surgeons were trained in neurosurgery in the USA. Although its facility was of low quality, military medicine was the seed of modern neurosurgery in Korea. Many neurosurgeons from foreign countries, mainly the USA, served in Korea. Korean doctors learned neurosurgery on the battle field [3].

The Korean Neurosurgical Society was founded in 1961. Many foreign scholars visited Korea to teach us, such as Dr. Suzuki (1975), Dr. Taveras (1978), Dr. Sweet (1983), Dr. Tew (1984), and Dr. French (1988). Shunt devices were not available in Korea until the late 1960s. Until that point, it was difficult to diagnose posterior cranial fossa tumors. Congenital lesions were left untreated because of poor prognosis and poor economic status. In this difficult period, a cerebral hemispherectomy for paragonimiasis in a child with intractable seizure was successfully performed in 1958 by Dr. Bo-Sung Sim [3]. This success encouraged many young doctors to become neurosurgeons. In the 1970s, Dr. Yoon Sun Hahn, who was trained in pediatric neurosurgery under the guidance of Dr. Raimondi, spent 2 years in Korea. Computerized tomography (CT) became available in the late 1970s. Then, the pioneers of Korean pediatric neurosurgery were trained abroad: Dr. Joon-Ki Kang, Dr. Joong-Uhn Choi, Dr. Byung-Kyu Cho, and Dr. Hoon-Gap Lee. The Korean Society for Pediatric Neurosurgery (KSPN) was founded in 1987 and began active scientific and educational activities with the help of teachers from the world. Moreover, 
Fig. 5 Dr. Jong-Wook Lee was $a$ man of action, a man of response, and a man of compassion (courtesy of Jun-Wook Kwon, M.D., DrPH)
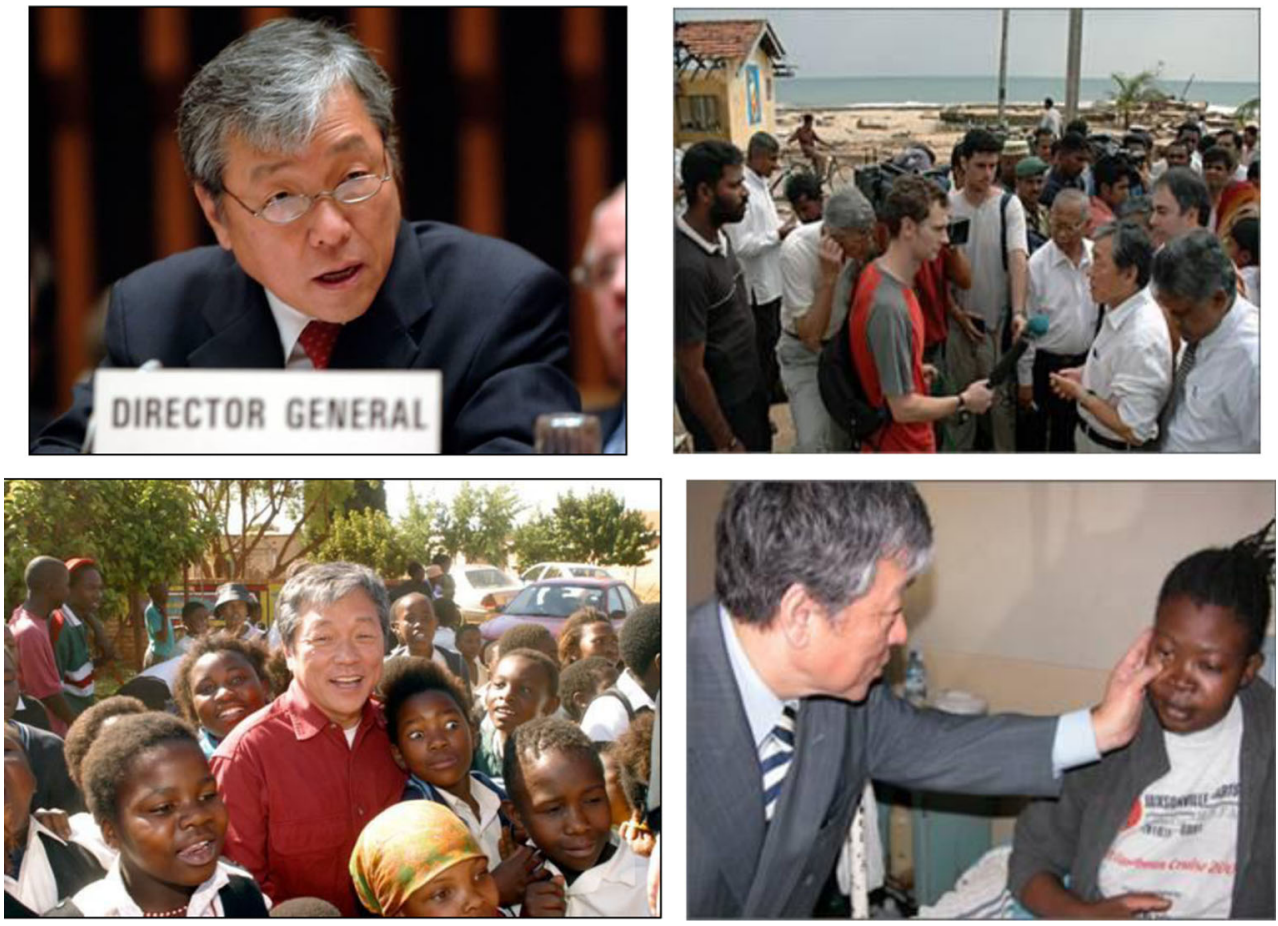

the International Society for Pediatric Neurosurgery (ISPN) meeting of 1991 was held in Seoul, hosted by Dr. Joon-Ki Kang with Dr. Joong-Uhn Choi serving as the secretary. Pediatric neurosurgery in Korea grew with the increased number of specialists and specialized hospitals, improved level of patient care, initiation of clinical and laboratory research, and establishment of fellowships. There were three factors in this growth: (1) the pioneers, Dr. Kang, Dr. Choi, and Dr. Cho, (2) educational aid from the world, and (3) nationwide economic growth. A nationwide health insurance system was introduced in the

Fig. 6 Dr. Tae-Seok Lee (also known as John Lee, S.D.B.) did his best to bring hope and blessing from God to the people in Tonj, where he worked as a religious priest, medical doctor, teacher, and conductor of a brass band (courtesy of Salesians of Don Bosco)
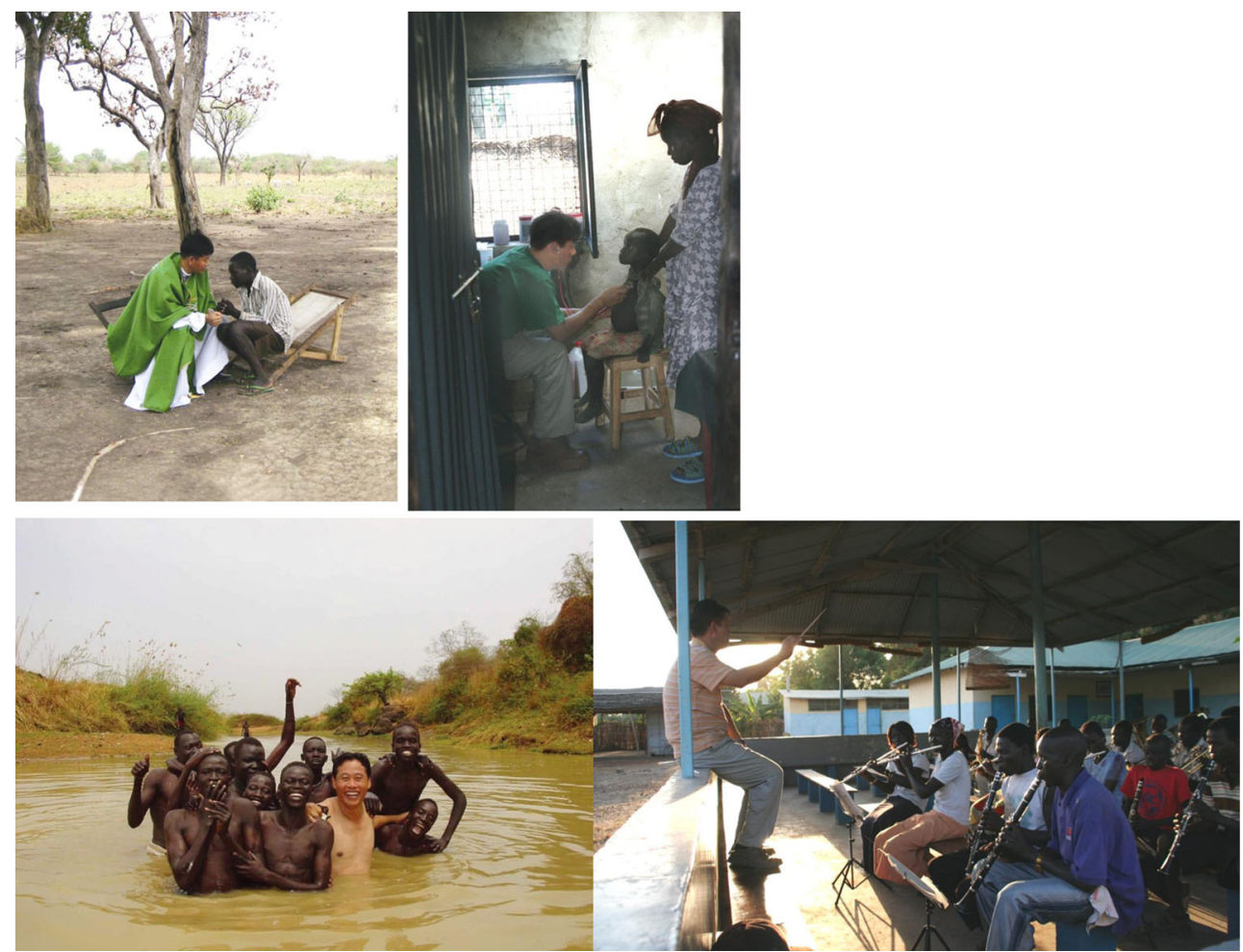
Fig. 7 Dr. Sung-Tae Hong was involved in the neglected communicable diseases control projects in Sudan, including schistosomiasis control and clean water projects while keeping his position at Seoul National University College of Medicine (courtesy of Sung-Tae Hong, M.D., Ph.D.)
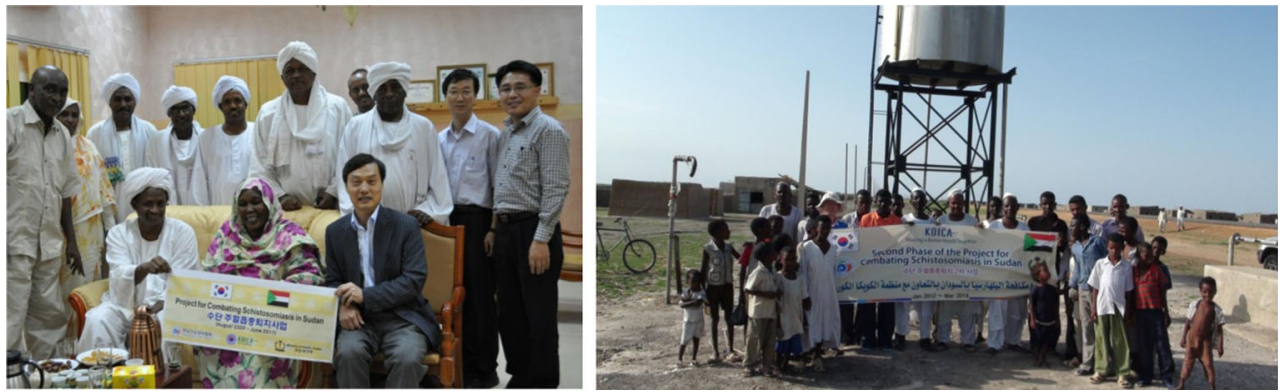

1980s. The GDP per capita increased by 272 times over 50 years: from US\$87 in 1962 to over US\$23,000 in 2012. However, patrons from the world played more important roles than the economic growth of Korea. I have listened to inspiring lectures from the great figures of pediatric neurosurgery who visited Korea to teach us: Dr. Yoon Sun Hahn and Dr. Tae Sung Park, both Koreans working abroad, and Dr. Raimondi, Dr. Lapras, Dr. Hoffman, Dr. Choux, Dr. McLone, Dr. Bagwati, Dr. Mori (Koreaki), Dr. McComb, Dr. Rekate, Dr. Pierre-Kahn, Dr. Sato (Kiyoshi), Dr. Sato (Osamu), Dr. Hockley, Dr. Walker, Dr. Pang, Dr. Abbott, Dr. Mutluer, Dr. Oi, Dr. Sutton, Dr. Rutka, and many others from the world.

\section{Two models of volunteer medical service in Sudan}

As a recipient of such generosity from the world, the KSPN must make a contribution to the world.

Here are two examples of voluntary medical service by Korean medical doctors in Sudan; one we cannot follow, but the other we may.

Dr. Tae-Seok Lee (also known as John Lee, S.D.B.) was born in Korea in 1962. After graduating from Inje University College of Medicine, he became a religious priest, Salesians of Don Bosco, in the Catholic Church instead of being a "usual" doctor. In 2001, he traveled to Tonj, a small village in South Sudan. There, he served for 8 years. Tonj was ravaged by poverty and communicable diseases, such as cholera. Working as a religious priest, medical doctor, teacher, and conductor of a brass band, Dr Lee did his best to bring hope with the blessing of God to the people in Tonj (Fig. 6). In 2008 , during a vacation in Korea, he was diagnosed with stage III rectal cancer and he died in 2010 at age 47. Everyone in Tonj cried for Dr. Lee and the brass band played songs in his memory [4].

Another example is Dr. Sung-Tae Hong who was born in 1954. He was my classmate at Seoul National University and graduated in 1979. He majored in parasitology and tropical medicine and joined the faculty of Seoul National University College of Medicine in 1986. In 2009, he began to work for Sudan as a member of the Korea International Cooperation Agency (KOICA) and specialist in topical medicine, keeping his position at the university. He was involved in the Neglected Communicable Diseases Control Projects, including Schistosomiasis Control and Clean Water Projects (Fig. 7). He also arranged and made funds for 16 patients who needed hospital care. Sometimes, he personally paid for the hospital bills. A patient with sincipital encephalocele was brought to Korea and underwent surgery. In another case, a girl came to Dr. Hong suspecting pregnancy. However, it was confirmed as ascites, which was caused by protein deficiency. After treatment with nutrition, the girl recovered from the ascites and was actually able to become pregnant. Her baby has another name, "Korea Hong."

Although we are tied to the busy activities of our own, we must spare time, energy, and spirits for those in need, as our patrons from the world have done for pediatric neurosurgery of Korea.
Fig. 8 a Dr. Vilaixane from Laos. b Dr. Adriansyah from Indonesia and Dr. Mukherjee from Bangladesh visited Korea to observe clinical activities in pediatric neurosurgery
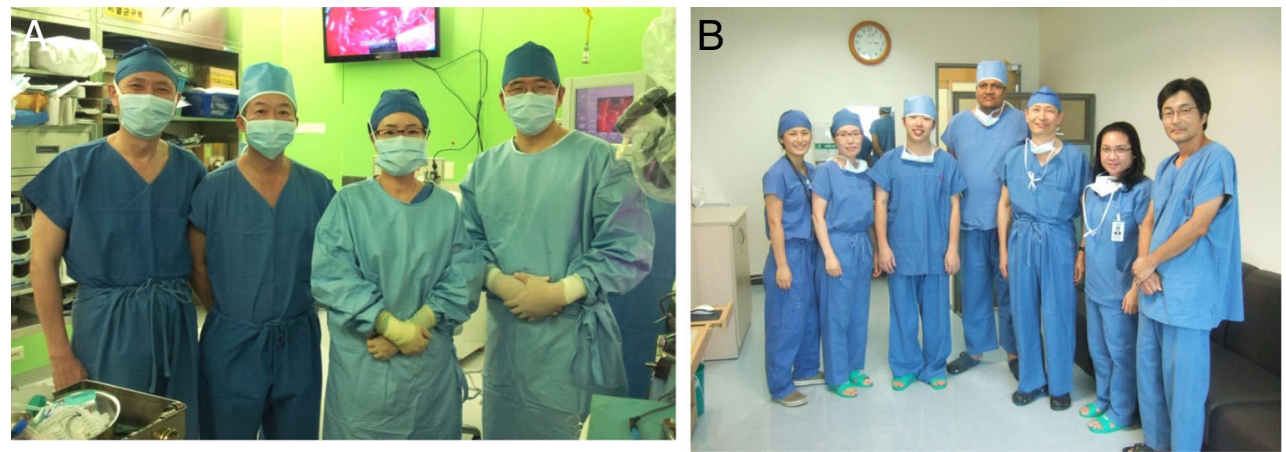
Fig. 9 The gala dinner and the logo of ISPN2010 Jeju meeting
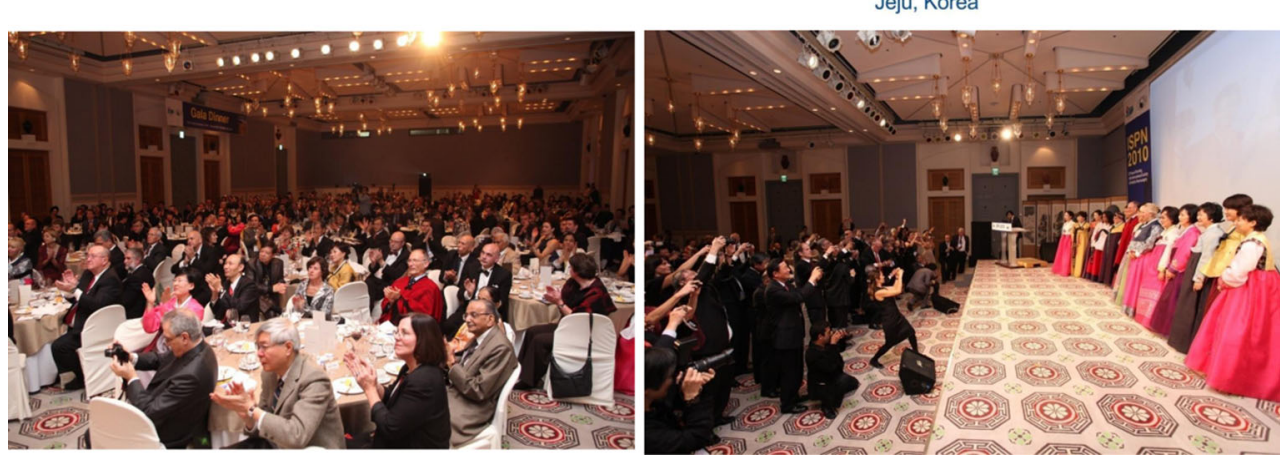

Contribution of KSPN to the world: minimal duty as a recipient of so much generosity from the world

KSPN has tried to contribute to the world in many ways in return for the help Korea has received.

Recently, we have published 40-60 articles in international journals each year. I would like to give some examples of earlier times. In 1987, Dr. Joon-Ki Kang and his team measured blood flow of the spinal cord and somatosensory evoked potential (SEP) in a cat tethered spinal cord model and showed decreased spinal cord blood flow with deterioration of SEP which was improved after untethering [5]. This is a historic article. In 2002, Dr. ByungKyu Cho and his team published an article introducing a surgical method of combined indirect revascularization for the anterior cerebral artery (ACA) and middle cerebral artery territories that dramatically increased the cerebral blood flow in the ACA territory [6]. This article was selected as one of the representative operative advances of the decade and was republished by the Journal, Neurosurgery in 2008 [7]. In 2003, the same team described the whole process of secondary neurulation in chick embryos. They found the terminal balloon which resembles the terminal myelocystocele of human [8]. In 2004, Dr. Joong-Uhn Choi and his team published an article regarding their experience on the endoscopic disconnection for hypothalamic hamartoma with intractable seizure [9]. Dr. Joong-Uhn Choi invented an endoscopic approach, and Dr. Rekate adopted this method for his own cases and later reported a large series [10].

We have also participated in educational activities delivering lectures at various international educational courses, and inviting to Korea and training foreign doctors, especially from other Asian countries. Recently, we could start the ISPN-KSPN International Joint Fellowship through which Dr. Vilaixane from Laos and Dr. Adriansyah from Indonesia visited Korea (Fig. 8).

We are also involved in administrative activities. Dr. Kang and Dr. Choi have served as presidents and others as chairpersons of committees of the ISPN.
In 2010, we held the ISPN meeting on Jeju Island. It was an undertaking to which all KSPN members contributed in the middle of a global economic recession. We provided first-rate scientific content, a pleasant environment and good food, and warm hospitality. We treated delegates with trainee awards, deeply discounted accommodations, free social activities and official tours, unlimited food and wine, and more. We were happy to see that all the attendees enjoyed the meeting (Fig. 9).

\section{Conclusion}

This is a report to our patrons from the world about the development of pediatric neurosurgery in Korea and the lessons from Dr. Jong-Wook Lee, "Contribution to the World." Our experience may serve as a model for providing aid for pediatric neurosurgery to developing countries.

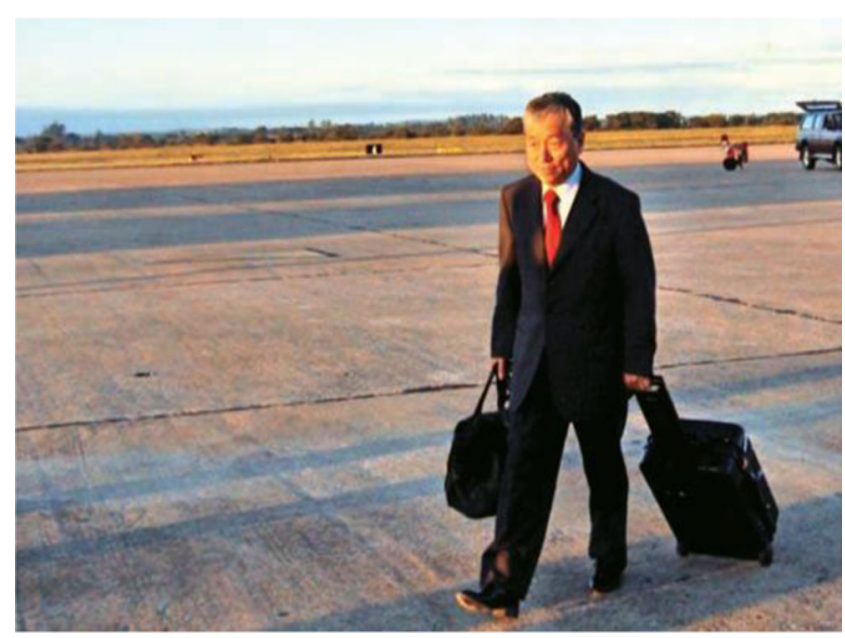

Fig. 10 Dr. Jong-Wook Lee carries his baggage at sunset. He always carried his bags by himself. His dream will last in our hearts forever (courtesy of Jun-Wook Kwon, M.D., DrPH) 


\section{Epilogue: Dr. Jong-Wook Lee, thereafter}

Sadly, in 2006, Dr. Lee died of a stroke in Geneva. Now, he became a man of legacy. "The world has lost a great man. He was a strong voice for the right of every man, woman, and child to health prevention and care, and advocated on behalf of the very poorest people", Mr. Kofi Annan, secretary general of the UN, stated. "Dr. Lee worked tirelessly to improve the health of millions of people, from combating tuberculosis and HIV/AIDS to his aggressive efforts to eradicate polio. He provided tremendous leadership to the international community as it confronted the challenges of the twenty-first century, including the threat of an influenza pandemic. Dr. Lee's outreach to world leaders and entities increased awareness of potentially devastating public health dangers." Mr. George W. Bush, president of the USA, said. Mr. Choong-Ho Lee (also called Hogeon or Tadahiro), the son of Dr. Lee, said: "My father was a man of action, whose adventurous spirit led him to experience more, see more, and do more. This spirit made him great at work, and great at life." [11].

In 2007, the Korean government established a memorial prize for Dr. Lee to inspire young leaders to follow in his footsteps. Now, his wife, Mrs. Reiko Kaburaki Lee works in Peru to help poor women and children.

Dr. Jong-Wook Lee: his dream will last in our hearts forever (Fig. 10).

Thank you for your attention.

Acknowledgments I would like to express my sincere gratitude to Dr. Jun-Wook Kwon (for the photos of Dr. Jong-Wook Lee), Salesians of Don Bosco (photos of Dr. Tae-Seok Lee) and Dr. Sung-Tae Hong (photos of himself). Some photos have been taken from the webpages of the UN (a photo of Mr. Ban) and Wikipedia (an old logo of the USAID). I owed to Dr. Ji-Yeoun Lee during data collection for this manuscript.

\section{References}

1. Wikipedia Ban Ki-moon. https://en.wikipedia.org/wiki/Ban_Ki_ Moon

2. Kwon JW (2007) Do, if you believe it is right: experience more, see more, do more. Kaya Books, Seoul [Korean]

3. Kim OJ, Park JY (2011) SIM, Bo-Sung: a pioneer of neurosurgery in Korea. Seoul National University Press, Seoul Korean

4. Lee TS (2011) Would you be my friends? 2nd edn. Bible \& Life Publications, Seoul [Korean]

5. Kang JK, Kim MC, Kim DS, Song JU (1987) Effects of tethering on regional spinal cord blood flow and sensory-evoked potentials in growing cats. Childs Nerv Syst 3:35-39

6. Kim SK, Wang KC, Kim IO, Lee DS, Cho BK (2002) Combined encephaloduroarteriosynangiosis and bifrontal encephalogaleo(periosteal)synangiosis in pediatric moyamoya disease. Neurosurgery 50:88-96

7. Kim SK, Wang KC, Kim IO, Lee DS, Cho BK (2008) Combined encephaloduroarteriosynangiosis and bifrontal encephalogaleo (periosteal) synangiosis in pediatric moyamoya disease. Neurosurgery 62(6 Suppl 3):1456-1464

8. Yang HJ, Wang KC, Chi JG, Lee MS, Lee YJ, Kim SK, Cho BK (2003) Neural differentiation of caudal cell mass (secondary neurulation) in chick embryos: Hamburger and Hamilton Stages 16-45. Brain Res Dev Brain Res 142:31-36

9. Choi JU, Yang KH, Kim TG, Chang JH, Chang JW, Lee BI, Kim DS (2004) Endoscopic disconnection for hypothalamic hamartoma with intractable seizure. Report of four cases. J Neurosurg 100(5 Suppl Pediatrics):506-511

10. Rekate HL, Feiz-Erfan I, Ng YT, Gonzalez LF, Kerrigan JF (2006) Endoscopic surgery for hypothalamic hamartomas causing medically refractory gelastic epilepsy. Childs Nerv Syst 22:874-880

11. Wikipedia Lee Jong-wook. https://en.wikipedia.org/wiki/Lee_Jongwook 